\title{
DISEASES OF THE COLON AND RECTUM JOURNAL
}

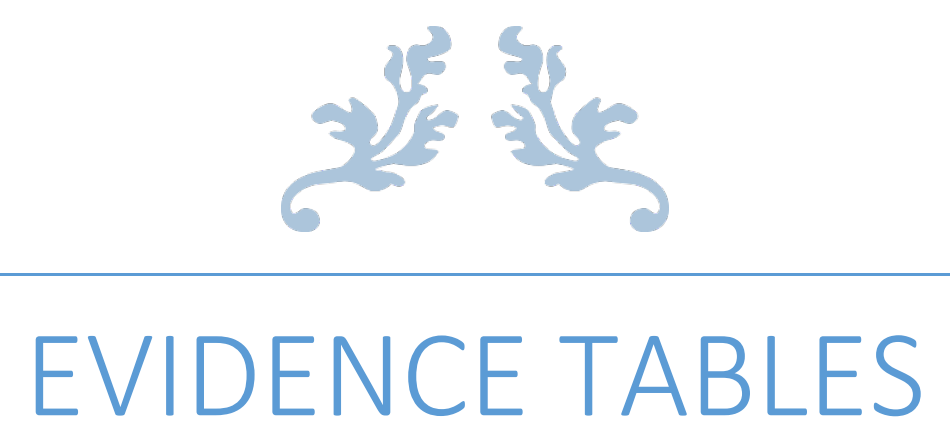

Clinical Practice Guidelines for the Use of Bowel Preparation in Elective Colon and Rectal Surgery Prepared on Behalf of the Clinical Practice Guidelines Committee of the American Society of Colon and Rectal Surgeons

\begin{tabular}{|c|}
\hline Postoperative Nausea and Vomiting (PONV) Strategy 1 \\
\hline Postoperative Nausea and Vomiting (PONV) Strategy 2 \\
\hline$\underline{\text { Postoperative Nausea and Vomiting (PONV) Strategy 3 }}$ \\
\hline$\underline{\text { Mechanical Bowel Preparation (MBP) Alone }}$ \\
\hline$\underline{\text { Mechanical Bowel Preparation (MBP) + Oral Antibiotic Bowel Preparation (OABP) }}$ \\
\hline$\underline{\text { Oral Antibiotic Bowel Preparation (OABP) Alone }}$ \\
\hline$\underline{\text { Rectal Enemas }}$ \\
\hline$\underline{\text { Clostridium Difficile }}$ \\
\hline
\end{tabular}

